\title{
Effect of Materials in Life Cycle Energy Assessment: A Case Study of a Single Storey Building
}

\author{
C. Sivapragasam ${ }^{1}$, PL. Meyyappan ${ }^{2}$, Rithu Christy ${ }^{3}$, V. Akila Reddy ${ }^{4}$ and S. Karthiga ${ }^{5}$ \\ ${ }^{1}$ Senior Professor, ${ }^{2}$ Associate Professor, ${ }^{3,485}$ UG Students, ${ }^{1,2,3,4 \& 5}$ Department of Civil Engineering, \\ Kalasalingam Academy of Research \& Education, Krishnankoil, Tamil Nadu, India \\ E-Mail: sivapragasam@klu.ac.in, meyyappan@klu.ac.in
}

\begin{abstract}
Life Cycle Energy Assessment (LCEA) of buildings is commonly being adopted as a tool to evaluate the environmental effects of a building throughout its entire life cycle to enhance the building sustainability. The different phases in the LCEA of a building involve the extraction \& manufacturing of building materials, construction, operation, maintenance and demolishing. It measures all inputs to a building and all outputs (emissions) released to the environment in all the phases. This study particularly focuses on the 'operational' phase of the LCEA and recommends what materials changes in some of the building components under Indian conditions can lead to lower energy consumption. The case study considered is a single storey building with a plan dimension of $10 \mathrm{~m} \times 7 \mathrm{~m}$. eQuest software is used for energy simulation. An attempt is also made to study the influence of environmental impacts of the building key assembly components such as roofs and infill walls etc. It is strongly recommended that all structural designs should consider LCEA before it is approved.
\end{abstract}

Keywords: Life Cycle Energy Assessment, eQuest, Energy Simulation, Roofs and Infill Walls

\section{INTRODUCTION}

The resource utilization and environmental emissions caused by the different process of infrastructure project phases such as extracting raw materials, manufacturing, constructing, operating, maintaining etc., [1]. The life cycle energy assessment is one of the evaluating tools for assessing environmental impact of various types of materials used in the buildings [2]. Due to lack of planning and under utilization of materials causes various issues related to economic and sustainable perspective [4] [5]. Among the different phases of the life cycle, operational phases play a major role in the energy consumption scenario [3], [5]. The evaluation of operational energy is done by the energy simulation software such as Bim, eQuest etc. [5], [6]. Some of the researches are carried out in the developed countries like Europe in regarding with life cycle energy assessment in us and Europe but in India the energy consumption is only in the beginning stage. In this study, an attempt is made to study the operational phase of LCEA for a single storey building in eQuest software. It is also made to study the influence on the electric consumption due to the material change in the building components like roof and infill walls.

\section{BUILDING DETAILS}

The single storey masonry building is considered for the evaluation of operational energy. The building has the plan dimension $10 \mathrm{~m} \times 7 \mathrm{~m}$ as shown in fig. 1. The building has one door and two windows facing in north orientation. In east and west orientation walls has one window each. Slab thickness is taken as $150 \mathrm{~mm}$. South orientation wall has two windows. The height of the building is $3.5 \mathrm{~m}$ and the roof slab thickness is taken as $150 \mathrm{~mm}$. The building elevation is shown in fig. 2.

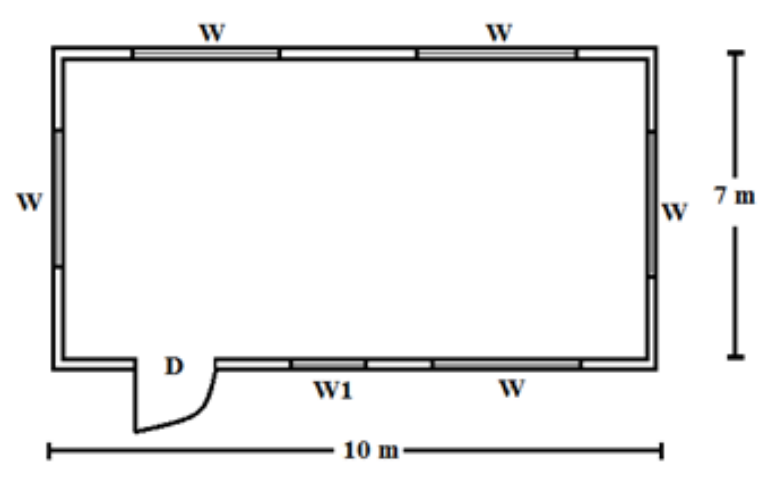

Fig. 1 Plan of the Building

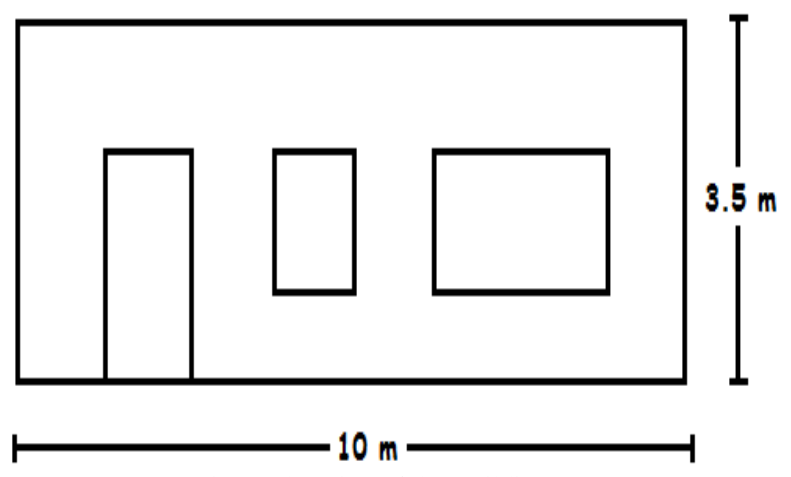

Fig. 2 Elevation of the Building

\section{INPUTS DETAILS IN E-QUEST}

The 'E-Quest' is the quick energy simulation tool which is widely used to caluclate the whole building's energy performancce. This tool is used to to develop 3-dimensional simulation models of a particular building design. These simulations incorporate the details of the building such as 
building location, orientation, wall/roof construction, window properties, as well as HVAC systems, day-lighting and various control strategies, along with the ability to evaluate design options for any single or combination of energy conservation measure(s). The following flowchart (fig. 3) will describes the procedure of E-Quest software in stage wise for obtaining the estimation of energy. The inputs in E-Quest are based on imperial units.

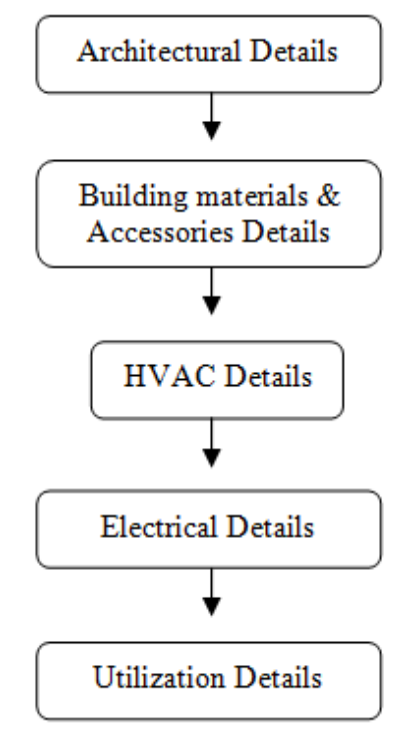

Fig. 3 Flowchart of E-Quest Stages

In architectural details, the details about the building area, layout, number of floors, shape of the buillding, building orientation, foot print dimensions, area per floors, floor heights and floor to ceiling height are essential in the Ist stage of e-Quest software. Table I describes the input summary of architectural details. In the II stage, building materials and accessories includes the details about the roof surfaces and grade walls, type of constructions, interior finish, exterior finish, insulations and exposures etc.

TABLE I INPUT SUMMARY OF ARCHITECTURAL DETAILS

\begin{tabular}{|c|l|l|}
\hline S. No & \multicolumn{1}{|c|}{ Parameters } & \multicolumn{1}{c|}{ Data } \\
\hline 1 & Building Area & 70 Sq.M \\
\hline 2 & Number Of Floors & $\begin{array}{l}\text { Above Grade : } \\
\text { Below Grade }: 0\end{array}$ \\
\hline 3 & Foot Print Shape & Rectangular \\
\hline 4 & Zoning Pattern & One Per Floor \\
\hline 5 & Building Orientation & Plan North \\
\hline 6 & Footprint Dimensions & $\mathrm{X}=10 \mathrm{M}, \mathrm{Z}=7 \mathrm{M}$ \\
\hline 7 & Floor To Floor Height & $3.5 \mathrm{M}$ \\
\hline 8 & Floor To Ceiling Height & $3.2 \mathrm{M}$ \\
\hline
\end{tabular}

It also includes door type and its dimensions, window type and its dimensions, types of window overhangs and finally roof skylights specifications as mentioned in the Table II.
TABLE II INPUT SUMMARY OF BUILDING MATERIALS AND ACCESSORIES DETAILS

\begin{tabular}{|c|l|l|}
\hline S. No & \multicolumn{1}{|c|}{ Parameters } & \multicolumn{1}{|c|}{ Data } \\
\hline 1 & Roof Surface & Concrete, Wooden \\
\hline 2 & Infill Walls & Masonry, Wooden \\
\hline 3 & Slab Thickness & 6 Inches \\
\hline 4 & Tiles Type & Ceramic \\
\hline 5 & Door Type & Single Leaf Glass \\
\hline 6 & Door Direction & North \\
\hline 7 & Door Size & 0.9 M X 2.1 M \\
\hline 8 & Window Size & 1.8 M X 1.2 M \\
\hline 9 & Window Position & 0.75 Cm(Sill Height) \\
\hline 10 & Window Direction As Per Plan. \\
\hline
\end{tabular}

In the III stage, details about HVAC includes type cooling system, cooling sources, air path as described in Table III. HVAC zones represents thermostat setpoints, cooling design temperature and air flows. Packaged HVAC equipment represents cooling system size, condensor type, efficiency.

TABle III INPUt Summary Of HVac Details

\begin{tabular}{|c|l|l|}
\hline S. No & \multicolumn{1}{|c|}{ Parameters } & \multicolumn{1}{c|}{ Data } \\
\hline 1 & Cooling Source & DX Coil \\
\hline 2 & Heating Source & Nil \\
\hline 3 & Cool System Type & Split Single \\
\hline 4 & Thermostat Set Points Range & $75^{\circ} \mathrm{F}$ To $85^{\circ} \mathrm{f}$ \\
\hline 5 & Cooling Design Temperature & $65^{\circ} \mathrm{F}$ To $75^{\circ} \mathrm{f}$ \\
\hline 6 & Air Path & Direct \\
\hline 7 & Air Flow & 0.50 Cfm/Sqft \\
\hline 8 & Efficiency & 1 (HVAC) \\
\hline
\end{tabular}

The electric details which include lighting load and plug load are to be provided and that corresponding details based on the activity area and occupancy of the building. The utilization and schedule details include the usage of electrical appliances, HVAC systems etc. as mentioned in Table IV w.r.t time, days and seasons.

TABLE IV INPUT SUMMARY OF ELECTRIC \& ITS UTILIZATION DETAILS

\begin{tabular}{|c|l|l|}
\hline S. No & \multicolumn{1}{|c|}{ Parameters } & \multicolumn{1}{|c|}{ Data } \\
\hline 1 & Lighting Load & 4.65 W/Sq.M \\
\hline 2 & Plug Load & 5.48 W/Sq.M \\
\hline 3 & Design Occupancy & 11 Sq.M / Person \\
\hline 4 & Occupancy & $100 \%$ \\
\hline 5 & Electric Usage & 7.00 Am To 7.00 Pm \\
\hline 6 & Days & Mon To Sun \\
\hline 7 & Season & 12 Months \\
\hline 8 & HVAC Timings & 7.00 Am To $11.00 \mathrm{Am}$ \\
\hline
\end{tabular}




\section{OPERATIONAL PHASE OF LCEA STUDY}

Based on the necessary input/requirements as mentioned from Table I - IV, are given in e-QUEST software and the model of the single storey building of plan dimension $10 \mathrm{~m}$ x $7 \mathrm{~m}$ is obtained in fig. 4. Three cases are considered for this LCEA study.

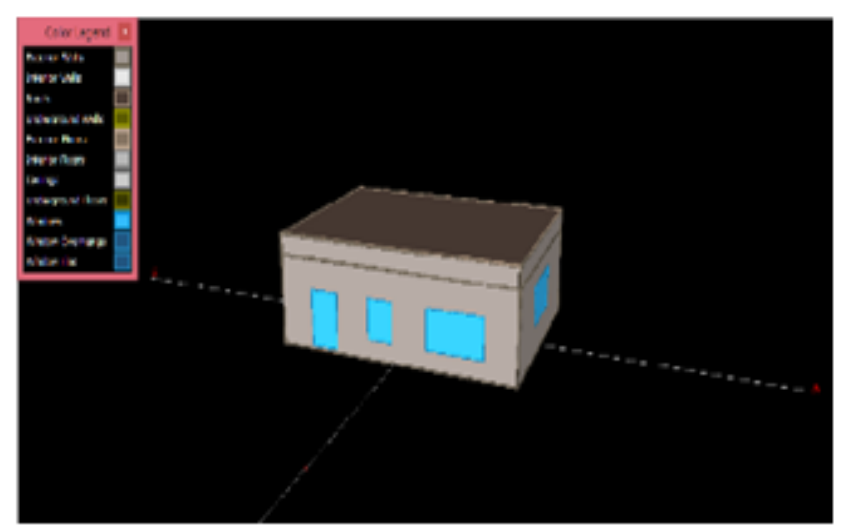

Fig. 4 Building Model

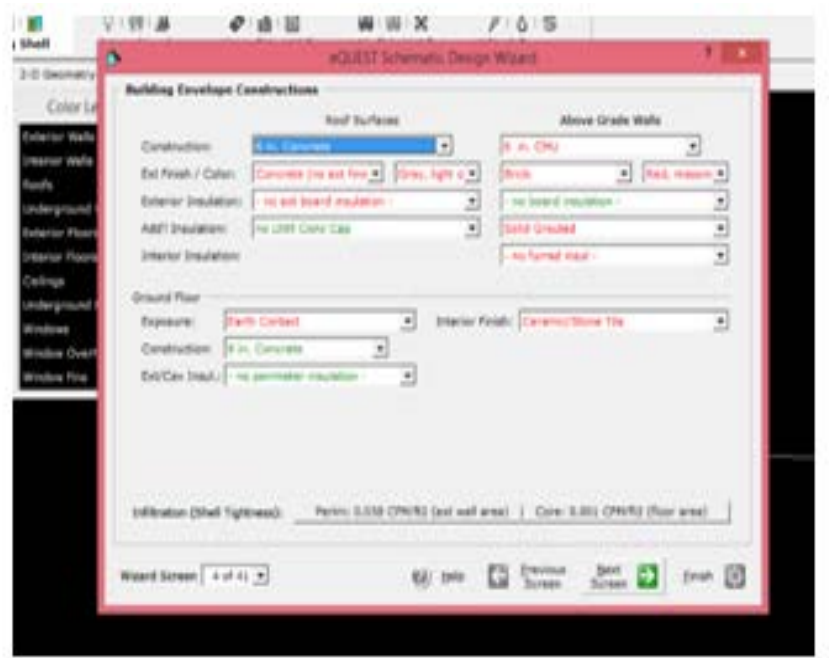

Fig. 5 Snapshot for Material Change Wizard

In case 1 , roof slab of the corresponding building is made up of RCC material and the infill wall is made up of masonry material. In case 2, the masonry infill wall is changed to wooden infill wall. Finally in the case 3, both the roof and infill wall of the building is made up of wooden material. Accordingly the changes in the material of the building components for each case have done in the building materials and accessories input stage. Fig.5 demonstrates the snap shot of the material change wizard in the e-QUEST software.

\section{RESULTS AND DISCUSSION}

The LCEA calculation for three all the cases were analysed in the e-Quest software. The results of the total energy consumptions $(\mathrm{kWh})$ for the various cases were tabulated on Table V. Fig. 6-8 shows the graphical representation of month wise electric consumption on various aspects for case 1,2 and 3 respectively.

TABle V Results Of ANnual Energy Consumption For All CASES

\begin{tabular}{|c|l|c|c|c|}
\hline \multirow{2}{*}{ S. No } & \multirow{2}{*}{ Aspects } & \multicolumn{3}{|c|}{$\begin{array}{c}\text { Annual Electric } \\
\text { Consumption (Kwh) }\end{array}$} \\
\cline { 3 - 5 } & & Case 1 & Case 2 & Case 3 \\
\hline 1 & Space Cool & 46.1 & 105.5 & 81.7 \\
\hline 2 & Ventilation Fans & 443.9 & 604.5 & 604.5 \\
\hline 3 & Area Lighting & 1273.1 & 1273.1 & 1273.1 \\
\hline \multicolumn{2}{|c|}{ Total } & 1763.1 & 1983.1 & 1959.3 \\
\hline
\end{tabular}

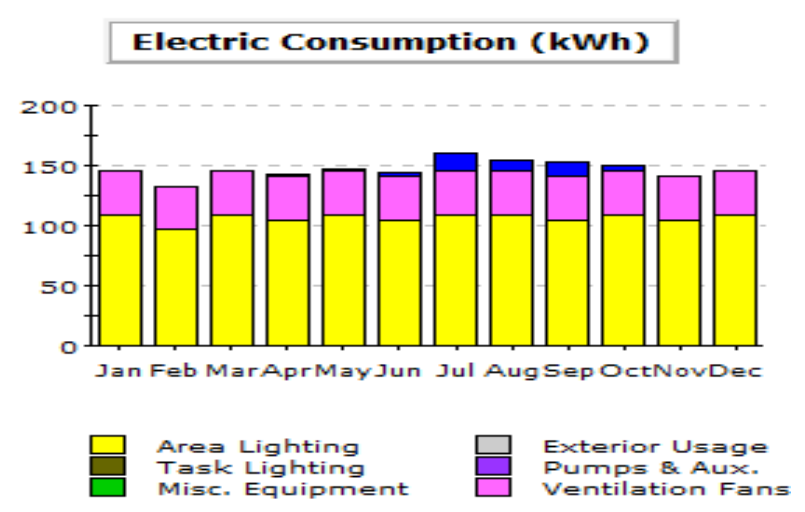

Fig. 6 Electrical Consumption for Case 1

Electric Consumption (kWh)

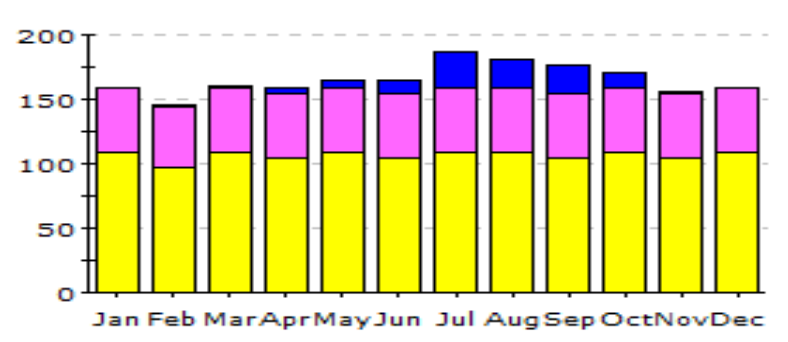

Area Lighting Task Lighting

Misc. Equipment

Exterior Usage Pumps \& Aux. Ventilation Fans

Fig. 7 Electrical Consumption for Case 2

Electric Consumption ( $k$ Wh)

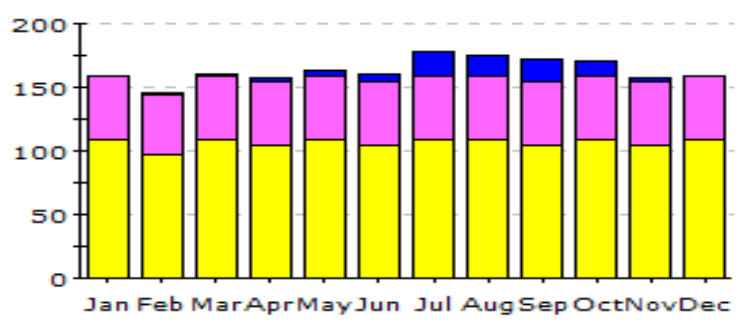

Area Lighting Task Lighting Misc. Equipment

Fig. 8 Electrical Consumption for Case 3 
Out of the total electric consumption, the area lighting is having $73 \%$, ventilation fans having $25 \%$ and remaining $2 \%$ is only for space cool aspects. It is also noticed that there is no change is seen on the aspect of area lighting even under the change of material. By changing the infill wall material from masonry to wooden, the electric consumption is increased to 2.28 times, however when the roofing materials are changed from RCC to wooden material the electric consumption is decreased by 0.8 times. In the midsummer the space cool aspects are seen higher than the rest of the seasons. In the month of month of Nov - Feb, there is no consumption. By changing the roof material from RCC to wooden material, the consumption is reduced by $40 \%$.

\section{CONCLUSION}

The change in material for the building component such as roof and infill wall has no effect on the aspects of area lighting, since the electric consumption values are same. On all the cases, it is observed that the maximum electric consumption (73\% of the total load) is on area lighting than space cool and ventilation fan aspects. By changing the infill walls from masonry to wooden material, the electric consumption is increased by $35 \%$. By changing roof material from RCC to wooden material, the effect will be visibly seen only on the aspects of space cool and it is observed that, the electric consumption is decreased by $20 \%$. Hence, the effect of material behaviour is must to be incorporated in the design stage itself to reduce the energy consumption level.

\section{REFERENCES}

[1] J. Stokes and A. Horvath, "Life Cycle Energy Assessment Of Alternative Water Supply Systems", International Journal of Life Cycle Assessment, Vol. 11, No. 1, pp. 335-343, Sep. 2006.

[2] M. M. Khasreen, F. G. Banfil, and G. F. Menzies, "Life Cycle Assessment and the Environmental Impact of Buildings: A Review", Sustainability, Vol. 1, No. 1, pp. 674-701, Sep. 2009.

[3] T. Ramesh, Ravi Prakash, and K. K. Shukla, "Life Cycle Energy Analysis of Buildings: An Overview”, Energy and Buildings, Vol. 42, No. 1, pp. 1592-1600, Oct. 2010.

[4] An Executive Guide: Life Cycle Assessment, International Council of Chemical Associations, 2014.

[5] A. M. F. De Araujo, and S. F Tavares, "Building Life Cycle Energy Assessment on Pre-Operation Phase Using BIM”, In Proc. SBE'16, pp. 28, 2016.

[6] S. Soni, K. Chowdary, and A. Sharma, "Institutional Building Energy Simulation”, International Research Journal of Engineering and Technology, Vol. 3, No.1, pp. 1160-1165, Nov. 2016. 